\title{
IMAGINARIO CREADOR Y POBREZA. ESTUDIO ETNOGRÁFICO ENTRE INDÍGENAS KICHWAS DEL CANTÓN AMBATO, PROVINCIA DE TUNGURAHUA- ECUADOR, QUE SALIERON DE POBREZA Y LOS QUE VIVEN EXTREMA POBREZA*
}

\author{
THE IMAGINARY CREATOR AND POVERTY. AN ETHNOGRAPHIC STUDY \\ AMONG THE INDIGENOUS KICHWAS FROM THE CITY OF AMBATO \\ IN TUNGURAHUA PROVINCE-ECUADOR, WHO HAVE OVERCOME \\ SITUATIONS OF POVERTY AND OF THOSE WHO LIVE IN EXTREME \\ SITUATIONS OF POVERTY
}

Judith Pinos Montenegro**

\begin{abstract}
Este trabajo muestra la diversidad de significados que otorgan indígenas kichwas del cantón Ambato, de la provincia de Tungurahua, a la pobreza; recupera su memoria de la infancia, en un entorno de carencias; los relatos transitan en un debate con las circunstancias y descansa en la lectura de su situación actual, así les permite a unos mirarse como sobrevivientes de un contexto de carencias, y a otros, manifestarse como quienes enfrentan una situación peor que la que tuvieron en su infancia. Los resultados del artículo privilegian la voz de los sujetos, ya que lo que importa es la mirada de las personas desde sus posiciones y condiciones, e identificar cómo se intersecan su pasado y su presente; un relato que indiscutiblemente está barnizado de varias capas de conceptos y que está en una construcción permanente. Pero cuyo aporte debe ser considerado para el accionar público e institucional.

Palabras claves: Pobreza, imaginario, indígenas.
\end{abstract}

This research addresses the diversity of meanings which give indigenous Kichwa of the Ambato Canton, in the province of Tungurahua, poverty; it recovers the memory of childhood, in an environment of deficiencies; stories are a debate with their circumstances and rests on the reading of current situation, so it allows them to look like survivors of a context of deficiencies, and others, manifested as those who face a worse situation that it had in its infancy. The results of the article privileged voice of the subjects, since what matters is the gaze of the people from their positions and conditions, and identify how intersect its past and its present; a story that is indisputably varnished multi-layered concepts and that is in a permanent construction. But whose contribution should be considered for the public and institutional.

Key words: Poverty, the imaginary, indigenous.

\section{Introducción}

Este artículo presenta los resultados de un estudio etnográfico realizado con indígenas de la nacionalidad kichwas (hablan kichwa y español); la investigación se desarrolla en Ambato, provincia de Tungurahua, localizada en plena sierra centro del Ecuador ${ }^{1}$, tiene 504.583 habitantes, de ellos el $12,4 \%$ se autoidentifican como indígenas y residen mayormente en la zona rural (INEC, 2010) (Foto 1). Sus actividades económicas principales están vinculadas a la siembra de ajo, cebolla y verduras; la cría de ganado y la producción de derivados lácteos; hay productores individuales pero también hay formas cooperativas y comunitarias e incluso organizaciones financieras, que surgieron entre 1999-2000, en que el Ecuador cambió de moneda y adoptó el dólar y los bancos endurecieron los requisitos para otorgar préstamos; los grupos indígenas concretaron alternativas financieras por medio de cooperativas de ahorro ${ }^{2}$. Los grupos indígenas cuentan con un sistema organizativo que tiene representación en el seno de la provincia de Tungurahua, y en su jurisdicción geográfica se reconocen los derechos ancestrales y el concepto de "comunero" como miembro con voz y voto en la toma de decisiones (que tiene carácter colectivo); por lo que para realizar esta investigación

\footnotetext{
* Resultado de investigación financiada por la Pontificia Universidad Católica del Ecuador (2014-2015).

** Pontificia Universidad Católica del Ecuador, Sede Ambato (PUCESA), Ambato, Ecuador. Correo electrónico: jpinos@ pucesa. edu.ec
} 


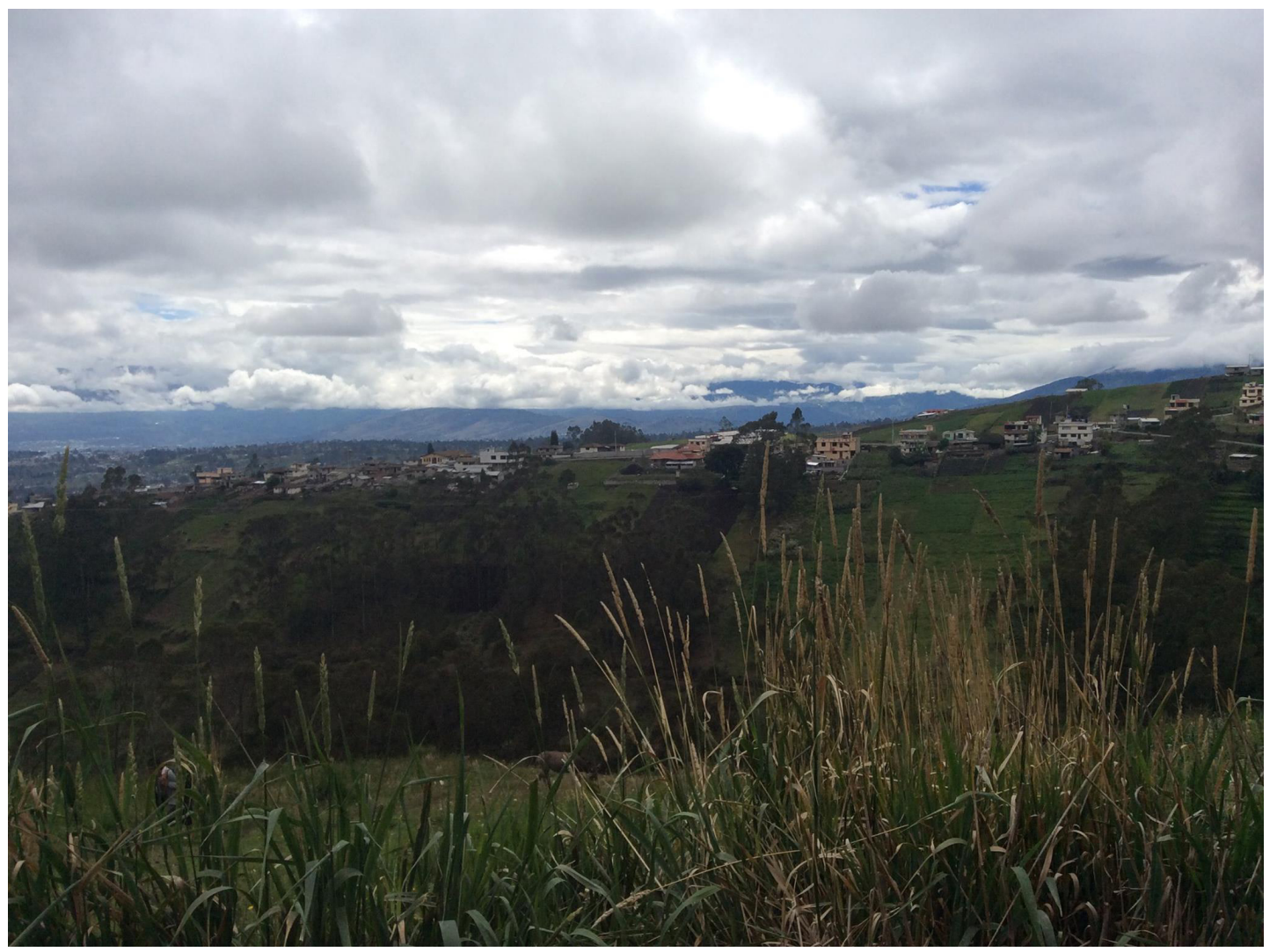

Foto 1. Pilahuín, Cantón Ambato, Tungurahua (Ecuador).

se requirió contar con el aval y el vínculo de los miembros de estas instancias.

Se utiliza la palabra imaginario como "la característica de las sociedades humanas, como actores ontológicos de su autocreación, esto se evidencia en el modo de ser sui géneris y no comparable con otros seres" (Castoriadis 2010:50). La investigación tiene un enfoque participativo, recupera la voz de los sujetos como un campo de significados donde se desarrollan relaciones sociales diversas; donde en cada sujeto conviven diferentes identidades con las que negocian, interpelan, redefinen y seleccionan elementos que les interesan, de acuerdo con la condición, posición y circunstancias a las que se enfrenten. Se abordarán los discursos como texto (Hall, Barth, Bajtin, Kristeva), formados por una diversidad de enunciados; donde el uso de los palabras es arbitrario y adquieren significado dependiendo de las decisiones de enunciación que establecen. Los relatos son ricos y complejos, discurren entre el interrogante respecto de la pobreza y la experiencia vital; se genera un aparente caos, que es ordenado mediante las coincidencias entre las afirmaciones de los sujetos.

La investigación siguió los siguientes pasos:

1. Presentación y validación de la propuesta de investigación, con las organizaciones indígenas y campesinas de la provincia de Tungurahua, y la institucionalidad pública y privada ${ }^{3}$ que trabaja el tema de pobreza.

2. Para precisar el concepto local de pobreza se convocó a un Foro ${ }^{4}$ específico con la participación de representantes indígenas del cantón Ambato y la institucionalidad pública a nivel nacional como provincial.

3. Para determinar a quién entrevistar se siguió la postura teórica de Apel, quien sostiene que cada contexto crea las condiciones de validez intersubjetiva de su pensamiento (Apel, 2004). La selección de aquellas personas que habrían superado dificultades y carencias se hizo con la Unidad de Movimientos Indígenas de Tungurahua y corresponden a ocho personas, 
de ellas solo una es mujer. Para identificar a aquellos cuyas circunstancias han empeorado, se pidió a la ONG CACTU (Confederación de Asociaciones Comunitarias de Tungurahua) un listado de personas 5 . Se priorizó la entrevista a cuatro personas, de ellas una es hombre y tres son mujeres.

4. La recolección de información se realizó por medio de grabaciones de audio (para las entrevistas, donde se recogen relatos de vida que parten con los recuerdos de la narración de la niñez, hasta llegar al momento actual) y video (para el Foro), se llevó un registro administrativo con firma de los participantes, constituyendo la memoria documental de las visitas en terreno. Los registros magnéticos fueron convertidos en texto digital y devueltos a los entrevistados para su aceptación y conformidad.

5. El análisis de la información se realizó con la ayuda del software Tropes ${ }^{6}$, para dar cuenta de la producción del discurso en torno a las verbalizaciones, lo que es usual en los estudios que implican relatos (Wanderer 2008; Brandom 1994; Escalante Gómez 2009), pues permite una rigurosidad y precisión identificando palabra por palabra, los elementos discursivos por el número de aparición, en relación al texto general.

6. La interpretación y síntesis se organiza mediante elementos que son comunes a todas las entrevistas y que develan los temas y afirmaciones que hacen las personas entrevistadas y se establecen en los siguientes elementos:

- El estilo discursivo ${ }^{7}$.

- El universo de referencia $1^{8}$

- El universo de referencia 2

- La modalidad verbal $^{9}$

- El uso de las negaciones

- La presencia del pronombre "yo"

Una vez que se analizan estos elementos se identifica el punto de vista de las personas sobre su situación y los temas comunes en las historias de vida:

- El tipo de discurso

- La negación

- Las dificultades

- Las caras de la identidad

- La niñez y el trabajo infantil

- La conexión con el entorno

- El concepto de pobreza

- El plan de vida

- Las decisiones que tomaron
7. Se muestra la voz de quienes dicen de sí mismos que superaron la pobreza y aquellos que piensan que viven una situación más precaria que la que atravesaron en su infancia.

8. Se ensayan conclusiones y se devuelve la información a las instancias validadoras del estudio.

En cuanto a la estructura de este artículo se presenta en la sección uno la diversidad conceptual respecto de pobreza; los discursos de quienes se dicen salieron de la pobreza están en la sección dos; en la sección tres la voz de quienes afrontan circunstancias de pobreza y en la sección cuatro se ensayan algunas conclusiones y reflexiones.

\section{La pobreza}

¿Qué es pobreza? Etimológicamente el término pobreza proviene de una raíz latina, pauperis, que se traduce como "el que produce poco" (Dávila 2010:115), este origen alude a la responsabilidad personal y esconde las condiciones del entorno en las que cada sujeto desarrolla su vida. En el mundo occidental y particularmente en la institucionalidad como el Banco Mundial, Naciones Unidas y los gobiernos estatales, utilizan la categoría pobreza como un índice; operativamente se clasifica a las personas en relación con el acceso a bienes y servicios; al igual que en su génesis el término inclina la balanza hacia la característica personal y esconde las responsabilidades estatales de cobertura de servicios. No obstante los términos generados desde las instancias institucionales no necesariamente gozan de consensos, ya que existen diversos contextos culturales.

Los países y organismos dicen que existe pobreza; pero a pesar de los esfuerzos para analizar en qué consiste este fenómeno ${ }^{10}$, es evidente que no se llega a una definición única, de lo que se deduce que la pobreza es un constructo históricopolítico, es decir, es un acuerdo al que llega el conglomerado humano que ejerce el poder y que no necesariamente recoge la opinión de otros actores como los pueblos. El Consejo Latinoamericano de Ciencias Sociales (CLACSO) realizó un glosario internacional respecto de pobreza ${ }^{11}$, que consta de 16.000 definiciones. Los discursos institucionales nacionales o extranjeros tienen una capacidad operativa concreta que se plasman en la distribución de recursos, prioridad de acciones y la categorización de seres humanos. Los registros 
pueden tener múltiples lecturas, desempolvarlos y darles voz a los que se han acallado puede generar incomodidades.

El Estado ecuatoriano señala a los pobres por medio del mapeo de los beneficiarios del Bono de Desarrollo Humano. En el Plan Nacional del Buen Vivir 2013-2017 se apunta a los grupos indígenas como más pobres en comparación a aquellos que se autoidentifican como los mestizos ${ }^{12}$ (SENPLADES 2014; 163, 399, 64, 116, 140, 161).

La pregunta que sigue es si la jerarquización estatal coincide con la definición de pobre en kichwa. En los últimos 10 años Ecuador ha hecho un esfuerzo por consolidar un diccionario de lengua kichwa, en este documento se puede evidenciar que el término pobre no tiene en kichwa equivalentes, hay términos como los siguientes:

- Lluchu adj. desnudo, pobre.

- Tsunzu adj. andrajoso; pobre.

- Wakcha adj. s. pobre. 2. viudo, 3. huérfano, animal o persona. Yaya, mama (Ministerio de Educación del Ecuador 2009).

Estos adjetivos aluden a carencias económicas (sin ropa, andrajoso) y afectivas (como huérfano), esta última tiene particular significado porque wakcha implica no contar con un tejido familiar que lo acoja, si se presta atención es sinónimo de orfandad, de ruptura con el soporte social que es la base de lo humano, alguien que es parte de una unidad superior (un Estado por ejemplo), no debería ser wakcha, porque alguien respondería por esa persona. ¿Acaso los Estados han generado muchos wakchas? En esta mirada sí, han dejado en la orfandad e indefensión a sus hijos. Existe el verbo charina que se traduce como tener, pero es un verbo que expresa posesión, pero que debe ser leído en compañía de un complemento y puede ser aplicado a cualquier cosa, tener ideas, tener bienes, tener sentimiento o cualquier otro aspecto. En la investigación encontramos que en las localidades indígenas del cantón Ambato se utiliza el término charikuna para aludir a los que "no tienen bienes", este término sería, a decir de los entrevistados, una adaptación a la relación con el español (Chango:2014; Ainaguano:2014). Por lo expuesto, en cuanto a su significado el término pobre difiere de la percepción latina; mientras en el latín pobre alude a la responsabilidad personal (producir poco), en kichwa los términos se acercan más a una situación de orfandad. En la sociedad kichwa estos términos tienen una notoria carga éticomoral; por un lado dan cuenta de una condición, pero por otra dan cuenta de una responsabilidad, la del tejido social; así, en kichwa bienestar se traduce como Sumak Kawsay, es vivir en armonía con el entorno y la comunidad.

\section{Los imaginarios de quienes salieron de pobreza}

\section{Los discursos}

Del análisis con el software Tropes se desprende que el discurso predominante es argumentativo. $\mathrm{La}$ explicación de sus ideas cobran fuerza mediante la evocación de recuerdos dolorosos, los que están presentes a lo largo de toda la narración. La puesta en escena en todos los casos es dinámica y activa; cada persona entrevistada, en este grupo, se muestra como hacedora de decisiones; contestaria frente a lo que consideró como injusto. El universo de referencia 1 , del discurso de quienes salieron de pobreza, está marcado por los intereses en las cuestiones sociales, conceptos generales y la educación, y la enseñanza, lo que es coherente con su actual situación. En todos los casos son líderes comunitarios de sus localidades y su preocupación y acción giran en torno a los mismos temas; pero también es coherente con su marco de referencia, para ellos en calidad de líderes y liderezas su rol implica evidenciar la desprotección del Estado en sus territorios. Su segundo universo de referencia 2 abarca la identidad y la familia, el tiempo y los grupos sociales; marginalmente respecto del espacio. El uso verbal que predomina es el fáctico, denota la dirección discursiva en la afirmación de hechos. Se reconocen indios, herederos de una historia, habitantes de un sector territorial donde los servicios elementales no llegaron y aún no llegan. Portadores de una acción diaria y de relaciones claves que les permiten vivir su actual momento.

\section{La negación y el yo}

Se usa la negación para expresar un reclamo, en el discurso es un reclamo contra el Estado, contra la usencia de servicios; así:

"No había servicio de salud en la comunidad" (Tixalema 2014). ${ }^{13}$ 
"Soy un profesor que nunca fue a la universidad y que se educó en las escuelas radiofónicas" (Lligalo, 2014). ${ }^{14}$

"No estábamos, preparados, no hubo cómo educarnos" (Cayambe 2014). ${ }^{15}$

"Las mujeres no estudiábamos" (Uñag 2014). ${ }^{16}$

"Mi madre no podía darme la educación y en mi comunidad solo existía hasta el tercer grado" (Tayupanta 2014). ${ }^{17}$

"Mi mamá no tuvo educación básica, es analfabeta, hasta ahora" (Ainaguano 2014). ${ }^{18}$

El "no" niega toda la oración, es decir, se usa como lo contrario a lo esperado; por tanto, se demanda que existan servicios de salud, universidad, preparación, acceso a estudio y alfabetización. Se asientan como un reclamo. El "no" de ausencia descubre a un ser "deseante" a la más pura usanza hegeliana, al luchar contra estas situaciones y no resignarse a las mismas, el sujeto se configura como un amo, un mandante acerca de la situación que es negada.

Los discursos presentan un uso intensivo del pronombre "yo", que en todos los casos supera el $50 \%$ del texto discursivo. Este pronombre enfatiza la vivencia de la persona entrevistada. Todo "yo" es un sujeto social que es constituido y se constituye en el discurso. Las personas usan el yo como un ordenador de la acción, así:

"Yo trabajé y luego volví a la escuela para terminarla a los 18 años" (Cayambe 2014). "Yo vi la necesidad de que para guiar a la gente, para pensar en un futuro mejor, debía estudiar y tomé la decisión" (Tixalema 2014).

"Yo fui a la escuela" (Lligalo 2014).

"Yo recuerdo ya estaba en sexto grado, terminé la escuela sin zapato, pero a mí me gustaba avanzar" (Uñag 2014).

"Yo contribuí a construir la capilla, el alumbrado público, el agua, el alcantarillado, la escuela" (Tayupanta 2014).

"Yo fui profesor y quise ser Director. Pasaron los años, me dediqué a la dirigencia indígena, fui representante comunal, parroquial, provincial y nacional en el seno de la Ecuarunari" (Ainaguano 2014).
Es evidente en estos enunciados que sujeto y objeto se construyen mutuamente "en su misma constitución" (Lujan 2007:54). Este "yo" es capaz de estudiar, afrontar las dificultades y de pensar en el futuro. Se evidencia en los discursos coincidencias respecto de tener necesidades y actuar sobre ellas.

\section{Las dificultades}

La dificultad o carencia permite a los sujetos verse como actores:

"Cuando murió mi mamacita, me acuerdo, yo casi no dormía, mi padre lloraba en la noche. Yo pensaba, llora porque no hay quien cocine, por eso llora. Decidí levantarme a las 4 de la mañana, a las 7 de la mañana la comida estaba lista y salía a pastorear los borregos, las tardes volvía a cocinar" (Tixalema, 2014).

"Murió mi mamacita, no había quién nos cocine, mi hermanito y yo aprendimos a cocinar, aún recuerdo una papa grandota..." (Lligalo, 2014).

"Yo saqué una beca para todos y eso nos permitía pagar los pasajes para estudiar" (Uñag, 2014).

"Yo sufría mucho, mi papá murió, mi mamá no podía darme la educación, yo terminé la escuela a los 11 años y seguí estudiando" (Tayupanta, 2014).

"Yo pensaba que ese apodo (el que me puso el profesor), me hace más popular" (Ainaguano, 2014).

Construyendo un símil con el dolor corporal, que se lee como una incomodidad sentida, que te mueve a actuar. Los hechos dolorosos se convierten en el motivo por el que el sujeto toma decisiones. Además, es importante resaltar que estos hechos son evocados de tal manera que demuestran profunda tristeza y se deduce que están aún presentes y acompañan su accionar.

Las dificultades con las que se enfrentaron pueden ser de distinta clase, no implica solo la carencia de bienes y servicios, así:

"El principal obstáculo eran nuestros padres... Le dije a mi padre -a mí me gusta-, entonces las monjitas me apoyaron, pude estudiar" (Uñag, 2014). 
"En el Colegio de Agricultura había internado, entré a estudiar, pero el internado era dirigido por un exmilitar, así que nos exigía que a las 9 de la noche todas las luces estén apagadas. Yo no quería esto... Frente a la dificultad del hospedaje en el internado decidí alquilar un cuartito por la Plaza Primero de Mayo, un cuartito de madera, pero era libre de estudiar a cualquier hora" (Tixalema, 2014).

"Los compañeros me ponían apodos, se burlaban, me alzaban el poncho, era terrible. Pero llegué a ser parte de la directiva del curso, era popular" (Ainaguano, 2014). ${ }^{19}$ "Se burlaban de mí, un indio con zapatos, pero yo no me dejaba vencer" (Lligalo, 2014). "El levantamiento indígena, lo hicimos contra las cantinas y los chulqueros" (Tayupanta, 2014).

"Ven mañana, ven pasado, el indígena al último, no nos atendían. Yo decidí luchar, reclamar" (Cayambe, 2014).

Estas personas usan la oposición como un motivo de reflexión, cuestionamiento y acción, los intereses contrarios evidencian que las personas entrevistadas se abrieron paso enfrentando a "otros", en ese movimiento, leen que sus metas y aspiraciones son diferentes e inclusive discordantes con la voluntad de otros. El conflicto, en su discurso, se resuelve cuando asumen decisiones constituyéndose en hacedores de su entorno y su mundo. El 100\% de las personas entrevistadas evocó un gran dolor al recordar el fallecimiento de su progenitor y la discriminación racial de la que fueron objeto. Se evidencia un importante ejercicio de simbolización, otorgándole un sentido diferencial al signo "dolor y a la dificultad", esta simbolización le permite cohesionar sus metas, recargar sus energías.

\section{Las caras de la identidad}

Las historias de vida consolidan un elemento fundamental, cada una de las personas se mira como "yo" indígena, existente, desafiante, dueño de un territorio arrebatado, uno con la tierra y actor de decisiones. El significante de etnia es simbolizado por los entrevistados como un "valor agregado" que los hace poseedores de derechos, de conocimientos únicos y de posibilidades de vida en comunidad. Un eje común en su discurso es que miran su contexto como la residencia en una zona donde no llegaron los servicios públicos estatales e incluso los más elementales como la educación y la salud, la ausencia de un Estado que olvidó su responsabilidad y los deja huérfanos, pero nunca impotentes.

\section{La niñez, el trabajo infantil y el rezago escolar}

La niñez constituye, en la mirada social y en la individual, una etapa importante que tiene características particulares.

"Sería bueno vivir la niñez, para muchos no nos fue posible. Porque desde la niñez se ha estado en las actividades junto con los padres" (Tixalema 2014).

"Mi sufrimiento de niño hasta ser joven y cuando apareció la luz a los 18 años cuando aprendí a leer y escribir bien" (Lligalo 2014).

"El pueblo indígena al último, peor si eras niño, los niños jamás tenían que sentarse, en el mejor de los casos iban sentados sobre los papás" (Ainaguano 2014).

"Mi coraje viene de la niñez, yo tuve ese valor y ese coraje; llegaba el chulquero y les llevaba a trabajar forzados a mi mami a mi padre. Yo niña no podía hacer nada" (Uñag 2014).

"Nosotros los indígenas (niños) vivimos en el páramo sin escuela, sin educación, recién en 1954 mi tío ayudó a formar una pequeña escuela" (Tayupanta 2014).

"No había medicinas para mi hermano que era un baldadito ${ }^{20}$. Mi hermano murió. Yo aprendí pronto a trabajar a los 12 años" (Cayambe 2014).

El signo niñez es simbolizado como una antítesis a la adultez, una etapa de indefención, se reclama que la infancia debe ser vivida con respeto, con educación, sin trabajo infantil. Esta mirada reivindica una coincidencia con el artículo 46 de la Constitución Ecuatoriana, cuando dice "se prohíbe el trabajo de menores de quince años, y se implementarán políticas de erradicación progresiva del trabajo infantil" (Asamblea Constituyente 2008). Es necesario evidenciar que el trabajo infantil en la zona rural ha sido un nodo del debate social, ya que en la 
concepción kichwa la incorporación de los niños al aprendizaje de las labores agrícolas constituye parte de su preparación para la vida. Si los entrevistados cuestionan el trabajo infantil, esto muestra un cambio en la percepción cultural. En el caso que nos ocupa todos realizaron actividades de trabajo infantil; pero el rezago escolar (que en efecto lo vivieron) fue compensado más tarde continuando sus estudios.

\section{Conectados y ejerciendo el liderazgo}

Las historias de quienes salieron de pobreza tienen como rasgo común que todos ellos estuvieron y están conectados a la vida cotidiana de su comunidad, son reconocidos como líderes. Aunque el Estado estuvo ausente, hubo acciones privadas de las ONG y la Iglesia católica que intentaron llevar alfabetización y ayuda a estos sectores. Las personas entrevistadas entraron en relaciones con estas y entre sus consecuencias, para el caso que nos ocupa, permitió que aspectos importantes de la vida se canalicen, cambiando para siempre las oportunidades de la gente:

"Mato grosso me dio una beca y la beca era para estudiar en el Verbo Divino de Guaranda" (Tixalema 2014). ${ }^{21}$

"En el seno de la Ecuarunari, llegué a ser dirigente comunitario, parroquial y nacional" (Ainaguano 2014). ${ }^{22}$

"El padre Tamayo nos hizo despertar, eso no lo desconoceré jamás" (Lligalo 2014). ${ }^{23}$

"Entonces las monjitas hablaron con mi padre, las monjitas me apoyaron y pude estudiar" (Uñag 2014).

"Terminé la educación gracias a un centro de alfabetización, luego seguí capacitándome en varias cosas" (Tayupanta 2014). "Gracias al finado ( Presidente) Roldós se formó la alfabetización y fui nombrado alfabetizador" (Cayambe 2014). ${ }^{24}$

El eje fundamental fue la educación, gracias a esta las personas aunque tarde tuvieron acceso a procesos educativos que partieron con programas de alfabetización. El rezago escolar forzado al que estuvieron sometidos fue superado y adquirieron un dominio del idioma español y la adquisición de conocimientos específicos de acuerdo con la profesión u ocupación que escogieron.

\section{"Pobres son los que vendan los ojos" (Tixalema, 2014)}

Se les preguntó si se sintieron pobres o si alguna vez fueron pobres. Estas personas rechazan el adjetivo de pobres, lo consideran un insulto, lo sienten ajeno. La memoria particular de dolor y carencia les sirve para afirmarse como sobrevivientes, como victoriosos sobre la injusticia y el abandono del Estado, al que lo asimilan a lo blanco, a lo mestizo; se afirman por medio de un discurso que los levanta como valiosos, como productivos, como capaces de realizar acciones trascendentales.

\section{El plan de vida}

Un aspecto interesante es que estas personas tienen muy claro lo que desean y lo que dicen harán en los próximos años y lo expresan como acciones en relación con su pueblo; hacen un enlace entre su pasado y su futuro, su discurso memorial los vincula con un pasado personal heroico, victorioso, son los sobrevivientes de la injusticia; ese pasado cimenta la mirada del futuro. Por tanto, este plan de vida garantiza una relación armoniosa con el entorno y un afincamiento de su liderazgo.

\section{El imaginario y las decisiones}

Las personas asimilaron su situación de privaciones y dolor, para a partir de esta leerse como actores capaces de transformar su situación, aunque a edades tempranas, los hechos dolorosos no los inmovilizan, sino se convierten en un hito que les convoca a tomar decisiones. Resumiendo, los discursos de quienes tienen hoy una condición mejor que en su infancia tienen los siguientes puntos de coincidencia:

1. Se reconoce como indígena, heredero de una cultura valiosa.

2. Vive eventos de privación y dolor, cuyo recuerdo se evidencia a pesar del tiempo y les resulta inspirador.

3. Actúa, realiza acciones fundamentales en su vida, pero principalmente estudia.

4. Está vinculado a la comunidad, acepta apoyo, se mantiene en conexión con su pueblo y su entorno.

5. Adquiere habilidades, consolida una profesión u ocupación.

6. Ejerce el liderazgo y permanece en su comunidad. 


\section{Los imaginarios de quienes permanecen en pobreza}

Se entrevistó a personas cuya infancia se desarrolló en el mismo contexto. Del largo listado de personas pobres ${ }^{25}$ a entrevistar el $73,12 \%$ corresponde a mujeres y el $26,88 \%$ a hombres, todas ellas atraviesan hoy circunstancias de carencia.

Las voces que se escuchan a continuación corresponden a personas que residen en viviendas "precarias", trabajan de manera temporal en cultivos ajenos o labores manuales (reciben una paga diaria); su posibilidad de movilidad hacia otros espacios geográficos resulta difícil, porque en su mayoría son mujeres (jefas de hogar) o con una gran cantidad de hijos (más de 6) y en el caso de hombres, son personas que tienen dificultades físicas. A la fecha de esta investigación son familias que reciben apoyos ocasionales de ONG y la cobertura estatal del bono de desarrollo humano. La mayoría no poseen un terreno propio, este aspecto es fundamental, lo que las coloca al margen de las decisiones de la comunidad, como se explicará más adelante.

\section{Los discursos de las personas en extrema pobreza}

Su discurso en el universo 1 de referencia gira en torno a situaciones generales, para decantar en enunciaciones respecto del tiempo y el dinero; el universo 2 de referencia es la identidad, la familia, la disponibilidad del tiempo y los centros de enseñanza (acceso a la educación).

Los discursos reflejan lo inmediato, el día a día, cómo resolverlo y ejecutarlo, frente a una sensación copresente en todos los discursos de que el tiempo les es escaso.

Del análisis con el software Tropes se desprende que el discurso predominante es básicamente narrativo, la particularidad de este es que ubica a los hechos como una historia, es contada y sirve para establecer distancia con la acción, así quien narra se aleja de lo "narrado". El siguiente estilo que se encontró en los discursos es el estilo descriptivo. El uso de los verbos es fáctico y estático.

La puesta en escena resalta una saturación subjetiva, es decir, la presencia de un yo que se confunde con la situación y con el escenario. "Yo soy pobre", es una frase que se repite en el $100 \%$ de las entrevistas, mientras que en los discursos de quienes salieron de la pobreza es una categoría ausente. Parece que estas personas al vivir situaciones de carencia asumen el concepto de "pobres" como parte de su identidad.

\section{La negación y el yo}

Semánticamente, resulta interesante revisar la negación. Como se observará, junto con la negación le acompaña un verbo, esto implica una negación analítica, es decir, adquiere un nuevo cuerpo, una nueva representación.

"Yo no sé leer, yo no sé curar, sé cocinar solo la pobreza, coladas así." (C 2014) (A 2014) (B 2014).

"No tenía papá" (A, 2014).

"Ya no hay cabuya, ya no hay quinua, ya no hay ocas, no hay cómo challir26" (B 2014).

"No hay. Ahora para comer compro en el mercado mayorista" (C, 2014).

Por un lado, la negación tiene como eje de referencia su "sí mismo", es usada como inventario de falta de destrezas y pérdida. Por otro lado, la negación marca distancia con aquello que dejaron de tener, y básicamente está vinculado al acceso a la comida y a la alimentación. La negación tiene una importante presencia sígnica, más que simbólica, a lo largo de los textos, de tal manera que en las frases usadas representa el 49,2\%.

\section{Las dificultades}

Desde los años 80 y hasta la fecha se hizo evidente que la pobreza tenía rostro de mujer y relación genérica, es decir, es producto de los acuerdos implícitos o explícitos que se establecían con sus parejas y que da cuenta de una inequidad en las relaciones y una subordinación de la mujeres (World Bank, 2012). Las mujeres de esta investigación afrontan su vida como madres de familias numerosas ${ }^{27}$, lo que deriva en una responsabilidad familiar, que en estos casos es asumida solo por ellas y cuando existe por sus hijas mayores. La atención a la familia demanda en la concepción tradicional, la responsabilidad de la mujer, lo que se traduce en jornadas intensivas de trabajo no remunerado:

"Me levanto en la mañana a las 5, me voy a las 10 en la noche a la cama" (A 2014). 
Las mujeres de estas historias trabajan 18 horas diarias (cuidan a su familia, trabajan temporalmente en labores diversas, son las responsables de los ancianos), en espacios sin cobertura de las necesidades básicas. El 100\% reconoce que está alejada de cualquier actividad comunitaria y organizativa.

Las decisiones acerca de su cuerpo y el número de hijos que desean tener, sigue siendo un tema de los "hombres".

"Llegué a dar a luz a mi último hijo y la doctora me preguntó y yo dije la verdad -mi marido no quiere que me ligue- dice que -voy a andar con otros hombres" (B $2014)^{28}$.

La violencia de género no es ajena a estas circunstancias:

"Hace ya un año, ya cuando mi hijo mayor tiene 18 años, me ha dejado de pegar, pero... sí me insulta" (C 2014).

En sus palabras está presente la dependencia económica y la imposibilidad de contar con un tejido social o red y relaciones que les apoye. Su relato transcurre mediante una sucesión de episodios trágicos. Aunque son "jefas de hogar", en su relato está presente la subordinación, sus aspiraciones, el tiempo para ellas, sus sueños, no logran aflorar en el discurso. Lo que se evidencia es la preocupación por los suyos, por la comida, por lo cotidiano que se lee como una tarea inconclusa.

\section{La niñez y el trabajo infantil}

La niñez es evocada como un momento de dolor, abandono y privación:

"Yo fui siguiendo a mi papá, fui al bus y me perdí... Regresé porque un vecino, me vio llorando, y dijo ven. Mi papá ahí, no me fue a buscar... (Llora)" (B 2014). "No pusieron a la escuela, yo trabajando no más, ayudando, ¿por qué? No sé por qué habrá sido... (llora) (E 2014).

"Mi papá dijo, verás, no tengo para ponerte en la escuela, ya no alcanza..." (Hace una pausa y llora) Ya no fui a la escuela (C 2015). "Cuando mi papá murió, mamá sacó de la escuela, no pudo mandar a la escuela" (M 2014).
Estas personas dejaron de asistir a la educación primaria y en la mayoría de los casos de esta investigación (89\%) se reconocen analfabeto-as. Las personas entrevistadas recuerdan a las figuras parentales como fuente de dificultades, al mismo tiempo identifican su niñez como el momento de indefensión y parálisis. Los derechos de los niños y niñas están mediados por la decisión de los cuidadores principales, pero es obvio que estas también responden a un contexto específico; contexto que en estos discursos desaparece para tener solo un responsable singular, lo que confunde al sujeto, ya que la fuente de cariño se convierte también en fuente de dolor.

\section{Desconectados y viviendo los cambios en el sector rural}

Las personas en extrema pobreza viven una circunstancia especial de desconexión con su comunidad. En su discurso, esto es resultado de la saturación de actividades y también porque no tienen acceso a un pedazo de tierra que les habilita para participar en los espacios comunitarios.

Ejecutar los roles doméstico-reproductivos resultan difíciles, en medio del cambio de los patrones de producción. Así por ejemplo: los cultivos tradicionales (Foto 2) han sido reemplazados por cultivos de fresa, lo que trae complicaciones para obtener otras hortalizas y vegetales con los que se alimentaban tradicionalmente; ya no existen grandes extensiones de nabos, coles y otros. A esta problemática se añade la densidad poblacional, lo que ha hecho que las zonas antes rurales estén densamente pobladas, no teniendo concordancia y distinción entre una zona rural o una zona urbana, quizá la diferencia está en la disponibilidad de servicios básicos.

En la zona se evidencia el fraccionamiento de la tierra, a tal punto que a pesar de la ordenanza que rige el cantón Ambato (GAD Ambato 2009), en la que se establece que los lotes mínimos tendrán una extensión en la zona rural de 240 metros, la posesión efectiva de vivienda llega a ser a partir de un acuerdo interno. En el proceso de investigación se encuentran grupos familiares de 10 a 12 personas que ocupan espacios no mayores a 100 metros, sin las condiciones básicas (Pinos, 2014). Esta realidad conforma un nuevo escenario, en el que como establece la organización, para ser "comunero" se requiere ser propietario de un 


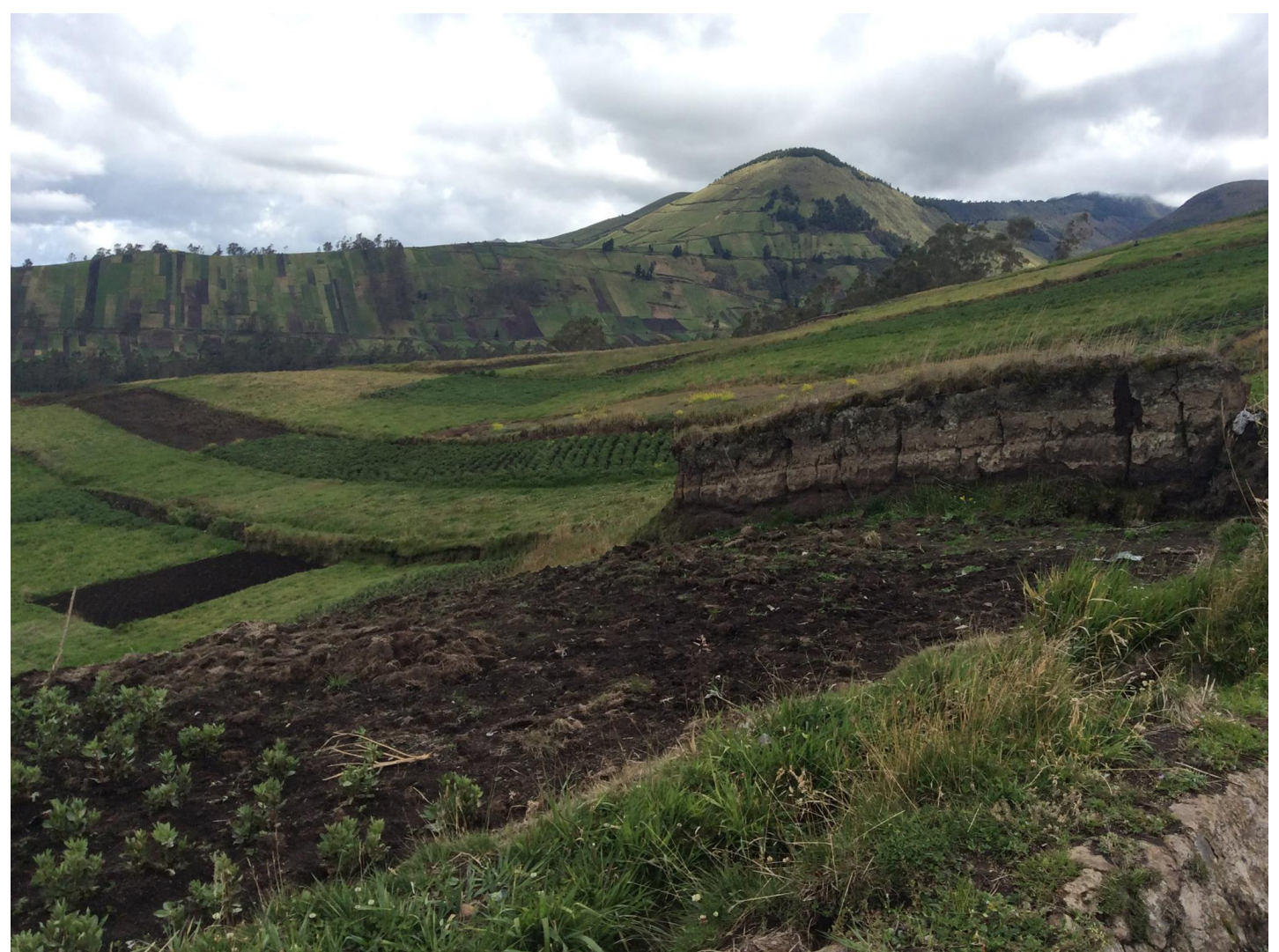

Fotos 2. Cultivos de papas y otros tubérculos como zanahoria en la zona rural de la Provincia de Tungurahua (sector Pilahuín).

pedazo de tierra, es evidente que ahora existen grupos familiares que no cumplen esta condición y que viven arrendando, "prestando" o junto con un familiar, de tal suerte que están alejados de las decisiones del colectivo, esto distorsionaría el concepto tradicional de lo comunitario presente en el imaginario kichwa. Tampoco son parte del mundo mestizo, pues las disposiciones legales impedirían también que sean reconocidos como propietarios. Están en una especie de limbo.

\section{Ser pobre}

Sobre si se consideran o no pobres, la respuesta fue que sí:

"Soy pobre, no tengo plata para comprar alguna cosa" (C 2014).

"Soy pobre, estoy operado, no hay cómo comer, tengo una deuda..." (L 2014).

"Pobre, pensar, dar de comer a guaguas, a mamá, con todo..." (M 2014).
El ser se constituye en la carencia, configura su identidad. En contraste con las historias de quienes salieron de la pobreza, se muestra una ausencia total de plan de vida, pareciese que la preocupación concentrada en lo cotidiano impide la mirada al futuro.

\section{El imaginario y las decisiones}

Las personas vivieron situaciones dolorosas (al igual que quienes salieron de la pobreza), pero en estas narraciones los hechos y sus sentimientos se funden con sí mismas, sus circuntancias actuales pareciesen ser un continuum con el pasado:

1. Se reconoce indígena, pero no lo mira como un valor agregado o una condición especial.

2. Recuerda hechos dolorosos y dificultades y aún las siente presente.

3. Se lee a "sí mismo" como incapaz de superar las dificultades.

4. Sufre aislamiento respecto de su entorno inmediato. 
5. No estudia ni consolida una ocupación identificable.

6. Su mirada se circunscribe al aquí y al ahora, arrastrando su pasado.

\section{Conclusiones}

Las culturas son dinámicas, incorporan elementos para explicar el mundo, como en el caso del término pobreza, que si bien no existía en el kichwa en Ambato, aparece el término charikuna (el que no tiene). Sin embargo sigue sin ser el equivalente a la etimología latina pauperis del término pobreza, "producir poco". Se requiere profundizar este aspecto en la búsqueda de encontrar viabilidad al mejoramiento de vida de los grupos humanos, a partir de su cosmovisión.

La categoría pobreza tiene muchos significados, pero un peligro latente que es el de la "clausura", el de encerrar a las personas dentro de un juego de poder y de exclusión. Las variantes kichwas, de este término, podrían obligarnos a romper las categorizaciones que parecen naturalizar todo, que esconden las causas estructurales; pero también merecen la pena identificar que nos gritan las voces de quienes cruzaron las barreras del entorno.

Ubicar al "otro", sea el Estado o el entorno como responsable, puede ser reduccionista; pero resulta difícil no hacerlo, pues las decisiones estatales canalizan recursos y beneficios hacia unos grupos, postergando a otros (política estatal). Pero reconocer la acción de personas que en entornos difíciles logran salir adelante, es darles la posibilidad para que sus voces convoquen la reflexión, la acción o provoquen al menos nuevas respuestas.

Del análisis contrastivo se despliegan al menos seis diferencias:

1. Acerca de la identidad, mientras para unos su origen carente los construye como vencedores, para los otros es solo fuente de dolor.

2. El dolor, siendo una variable presente en ambos grupos, es asumido por unos como un motivo para salir adelante, mientras que para el otro les inmoviliza.

3. La lectura del "sí mismo" es diferencial, los unos se sienten creadores, capaces, se presentan como tomadores de decisiones. Lo que se expresa en el uso de la negación. El uso de la negación puede ser un reclamo hacia el Estado, "no había agua, no había escuela, etc."; otros pueden usarla como una marca identitaria de déficit.

4. Un aspecto crucial es la red de relaciones, quienes salieron de la pobreza estuvieron y están formando parte de redes de relacionamiento comunitarias, provinciales, regionales, nacionales e internacionales. Mientras que los otros están aislados y sumergidos en la cotidianidad, porque carecen de tierra, no son comuneros, no tienen en estas sociedades tampoco derecho a voz y voto.

5. En los casos estudiados, todos vivieron rezago escolar, sin embargo, hay quienes estudiaron a partir de programas de alfabetización y consolidaron una profesión, una ocupación, así como un éxito productivo. Lo que es un aspecto que merece un nuevo estudio para comprender los mecanismos que usaron para lograrlo.

6. Respecto del eje plan de vida, el pasado muestra un minucioso plan de vida donde se miran conectados con su pueblo; mientras las personas en extrema pobreza circunscriben su plan al aquí y ahora, no hay el mañana en sus discursos. Indudablemente hay historias de vida que son producto de la ausencia del Estado; donde sus víctimas no son reconocidas como tal, la ausencia de registros que reconozcan la responsabilidad del Estado sobre el abandono de la gente sigue ausente, no existe una reparación necesaria que contribuiría a la mirada de las cifras de pobreza desde otra perspectiva. Los hallazgos permiten pensar que es necesario crear espacios de debate, donde las voces diversas (aunque incomoden) planteen cuestionamientos y alimenten con ideas a los estamentos tecnopolíticos y a la propia gente.

\section{Agradecimiento}

A la Unidad de Movimientos Indígenas de Tungurahua, a la CACTU, a la PUCESA y a las personas entrevistadas por su tiempo y paciencia. 


\section{Referencias Citadas}

Ainaguano, M.

(9 de octubre de 2014). Historia de vida (J. Pinos, Entrevistador).

Ainaguano, M.

(12 de octubre de 2014). Historias de vida (J. Pinos, Entrevistador).

Apel, K. O.

(7 de febrero de 2004). Reflexión Pragmático Trascendental. Lille, Francia: Invenio.

Asamblea Constituyente

2008 Constitución del Ecuador. Montecristi: Asamblea Nacional.

Banco Mundial

2002 La voz de los pobres. Desde muchas Tierras. Madrid: Ediciones Mundi Prensa.

Barth, F.

1976 Los grupos étnicos ys us fronteras. México: FCE.

Brandor, R.

2006 Making It Explicit: Reasoning, Representing and Discursive Commitmente. Cambridge: Harvard University Press.

Castoriadis, C.

2010 A Society Adrifth. New York: Fordham Univesity Press.

GAD Ambato

(12 de noviembre de 2009). Plan de Ordenamiento Territorial 2020. Ambato, Tungurahua, Ecuador.

Gómez, E.

2009 Método de Análisis de las verbalizaciones: una contribución del análisis textual y análisis conceptual mediante el uso de software. Encuentro, 32-48.

Hall, S.

1996 Questions of cultural identity. Londres: Sage Publications.

INEC, 2010.

2014 Inec.gob.ec. Obtenido de http://www.ecuadorencifras. gob.ec/censo-de-poblacion-y-vivienda/
Lujan, E.

2007 De la analogía al símbolo: vertientes de la hermenéutica. México: Univesidad Autonóma de Aguascalientes.

Ministerio de Educación del Ecuador

2009 RUNAKAY KAMUKUNA. Yachakukkunapa Shimiyuk Kamu. Quito: Ministerio de Educación del Ecuador.

MIT-MITA-AIET

2009 Testimonios sobre los procesos históricos de los movimientos indígenas y campesinos de Tungurahua. Cuenca: Gráficas Hernández.

Pinos, J.

2014 Diario de Campo, Investigación Imaginario Creador. Secretaría Nacional de Planificación. (2013). Buen vivir, Plan Nacional de 2013-2017. Quito: Senplades.

SENPLADES

2013 El Atlas de las desigualdades socioeconómicas del Ecuador. Quito: TRAMA EDICIONES.

Spicker, P., Álvarez, L. S., \& David, G.

2010 Pobreza: Un glosario Internacional . Buenos Aires: CLACSO.

Tropes. Zoom 7.0.

2010 Manual de Tropes. 1994.

Unidas, $\mathrm{N}$.

2009 Preguntas frecuentes sobre los derechos humanos Económicos, Sociales y Culturales. Géneva: Printed atUnited Nations.

Wanderer, J.

2008 Brandom, Durham. Hong Kong: British Library.

World Bank

2012 The Persistence of Gender Inequality. Washington: Onu.

\section{Entrevistas}

(18 de octubre de 2014). Historia de vida, de persona en extrema pobreza (J. Pinos, Entrevistador).

(14 de noviembre de 2014). Historia de vida (J. PInos, Entrevistador).

(8 de octubre de 2014). Historia de vida, de persona en extrema C1. pobreza (J. Pinos, Entrevistador).

( 2 de 3 de 2015). Entrevista a persona en extrema pobreza (J. Pinos, Entrevistador)

Cayambe, $\mathrm{N}$.

(5 de septiembre de 2014). Historia de vida (J. Pinos, Entrevistador).

Chacha, R., Lligalo, J., Uñog, R., Paucar, C., \& Toala, E.

(27 de Junio de 2014). I Foro Intercultual Significados de pobreza Ñukanchik Kawsaykuna. (J. Pinos, Entrevistador) Chango, B.

(14 de noviembre de 2014). Los términos pobres y pobreza (J. Pinos, Entrevistador).
(11 de octubre de 2014). Entrevista a persona de extrema pobreza (J. Pinos, Entrevistador).

Lligalo, J.

(8 de Agosto de 2014). Historias de Vida. (J. Pinos, Entrevistador).

(14 de septiembre de 2014). Entrevista a persona de extrema pobreza. (J. PInos, Entrevistador)

Tayupanta, E.

(8 de octubre de 2014). Historia de vida (J. Pinos, Entrevistador)

Tixalema, C.

(19 de septiembre de 2014). Historia de vida (J. Pinos, Entrevistador).

Uñag, R.

(12 de septiembre de 2014). Historia de vida (J. Pinos, Entrevistador).

Uñag, R.

(27 de Junio de 2014). Significados de la pobreza. 
1 En la zona rural del cantón Ambato están los pueblos Tomabela, Quisapincha y Chibuleo que residen en el cantón Ambato y el pueblo de Salasaka que está a 15 minutos de Ambato.

2 Un ejemplo, pero no es único es la Cooperativa Mushuc Runa, cuyo éxito financiero fue digno de mención en varios foros internacionales, www.mushucruna.com. Sin embargo, cuando consultamos si podíamos entrevistar a su personal, se nos manifestó que la forma de operar de esta entidad se distanciaba de la mirada del Sumak Kawsay (vínculo y servicio a la comunidad) y no se incluyó en la lista de personas entrevistadas, como se declaró en el proceso.

3 La Secretaría Nacional de Erradicación de Pobreza, el Gobierno Provincial de Tungurahua, la ONG CACTU, la cooperación alemana GTZ. La Unidad de Movimientos Indígenas de Tungurahua.

4 Se requiere la convocatoria colectiva para debatir temas de interés, por lo que por medio de un Foro representantes indígenas de todo el cantón Ambato concurrieron junto a sus dirigentes para analizar el término pobreza. Como parte del debate se presentó un panel con representantes designados por diferentes comunidades, tras las ponencias se pidió a los participantes del Foro que opinen respecto de una pregunta concreta: "qué es pobreza", el 58\% señala que la pobreza es carencia espiritual, mientras el $42 \%$ señala que son aspectos de carencia económica.

5 La CACTU opera bajo el apoyo de Child Fund y trabajan más de 25 años en la provincia de Tungurahua y llevan un seguimiento anual exhaustivo del progreso de familias de las comunidades que conforman su organización, mediante un registro administrativo llamado APR (Annual Progress Report), por sus siglas en inglés, así hay un archivo administrativo único, al que se tuvo acceso y se discutió con el equipo de técnicos a qué personas entrevistar.

6 Tropes es un software que trabaja en "división de las oraciones en frases, tratamiento de la ambigüedad de las palabras del texto, identificación de las clases de equivalentes y de sus relaciones, elaboración de estadísticas, detección de las ráfagas y de los episodios, detección de las frases relevantes" (Tropes, 2010).

7 "Hay cuatro estilos posibles: Argumentativo: que discute, que compara o critica. Narrativo: que cuenta una historia en un momento dado, en determinado lugar. Enunciativo: que establece una relación de complicidad o revela un punto de vista. Descriptivo: que describe algo o a alguien" (Tropes 2010).

8 "Los universos de referencia representan el contexto. Agrupan, en clases de equivalentes, las nociones desarrolladas en el texto objeto del análisis. El software detecta los universos de referencia utilizando dos niveles de representación del contexto (universo de referencia 1 y 2 )" (Tropes. Zoom 7.0, 2010).

9 Verbo: palabra que expresa, sea la acción por el sujeto, sea la existencia o el estado del sujeto, o bien la unión del atributo con el sujeto.

Los resultados se presentan en forma de listados de palabras tematizadas: todos los verbos se presentan en infinitivo (Tropes, 2010).
10 El literal b de la Declaración de Copenhague sobre Desarrollo Social de 1995 dice: "Más de 1.000 millones de habitantes del mundo viven en pobreza extrema y la mayoría padecen de hambre cada día... Especialmente en África" (Naciones Unidas, 1995).

11 En la página $\mathrm{N}^{\mathrm{o}} 21$ del documento se dice textualmente "En su conjunto el glosario ha sido ampliado a un total de 16.000 palabras" (Spicker, Álvarez, \& David, 2010).

12 El rezago escolar del $25 \%$, el déficit de cobertura de servicios básicos, el analfabetismo en mujeres indígenas del 27\%, la sensación de discriminación, la brecha en el acceso a salud, la desnutrición crónica en el $56 \%$ y grave en el 15\% de los niños indígenas.

13 Hombre, 72 años. Emprendedor, líder comunitario, graduado del programa de alfabetización.

14 Hombre, 65 años, exdirector nacional de educación bilingüe. Es líder comunitario, hoy trabaja como profesor con los primeros años de educación básica en su comunidad, enseña en lengua nativa a los más pequeños, por medio de anécdotas cuenta cómo llegó la primera escuela a su comunidad, está a punto de jubilarse.

15 Hombre de 62 años. Esta persona es un artesano, líder comunitario y emprendedor exitoso de muchas iniciativas.

16 Una mujer de 50 años, líder comunitaria, una de las primeras mujeres universitarias, hoy es parte de la gerencia de una cooperativa de ahorro y crédito, representa a todos los indígenas en la estructura de gobierno de la provincia de Tungurahua.

17 Hombre, 70 años, emprendedor, líder.

18 Hombre de 50 años, abogado, hoy líder comunitario y emprendedor.

19 Esta persona narra que estudió en un colegio público hispano de la ciudad de Ambato.

20 Se entiende "baldadito" como un discapacitado, especialmente, aquel que tiene afecta la motricidad gruesa. Es muy usual en la Sierra ecuatoriana el uso extensivo e intensivo de diminutivos, se entiende como una muestra de cariño y se aplica a casi todo sustantivo.

21 Mato grosso, ONG de carácter religioso que apoya iniciativas productivas y al sector rural.

22 Ecuarunari, organización indígena.

23 Se refiere al proceso de alfabetización emprendido por la Iglesia católica y dirigido por el padre Jesús Tamayo en Tungurahua.

24 El entrevistado se refiere a que en la Presidencia de la República de Jaime Roldós se inició una gran campaña de alfabetización para la zona indígena y rural.

25 El listado de personas pobres correspondió a la base de datos de la CACTU, organizaciones no gubernamentales que trabajan por 25 años en Ecuador y que ha proporcionado ayuda a diversas familias, realiza un "APR" que al traducir sus siglas significa Reporte Anual de Progreso, en cuyo instrumento se evidencia la historia de dichas familias. Estas personas están ubicadas entre el rango comprendido entre los 30 a 55 años, y su situación es mucho más precaria ahora comparada con la que afrontaron en su niñez.

26 Challir o chalar, la entrevistada se refiere a que las personas que son contratadas para cosechar, se les permite, una vez terminada la cosecha, recoger lo que ha sobrado. 
27 No solo son responsables de la familia directa, sino de la familia extendida, las madres y padres ancianos son considerados en estas comunidades como responsabilidad de las mujeres.
Las mujeres entrevistadas, la que más número de hijos tiene son 8 hijos y su edad es de 33 años. Y la que menos hijos tiene es 5 hijos, no llegan a los 40 años, todavía la probabilidad de maternidad está vigente. 